\title{
MEMÓRIAS DE UMA DESILUSÃO: Manuel Querino e as reformas urbanas de Salvador (1912-1916)
}

Bruno Pinheiro*

\begin{abstract}
RESUMO: É realizada neste artigo uma leitura historiográfica dos Lugares de Memória, na acepção de Pierre Nora, no contexto do pós-abolição em Salvador. Para essa proposta, são aproximadas as reformas urbanas realizadas na cidade entre 1912 e 1916 e as descrições presentes no livro de natureza memorialística Bahia de Outrora, publicado pelo intelectual negro Manuel Querino em 1916. Nessa avaliação, é acessada a noção de Arena Cultural, proposta por Richard Morse no contexto da história urbana, que propõe entender a implantação de projetos modernos a partir de seus produtos de cultura, noção que, frente às diferenças de raça e classe presentes na análise, é reelaborada a partir da ideia de subalternidade presente em Spivak. Por fim, apresenta-se um balanço de como a literatura de Querino, a partir dessas categorias operacionais, contribui no estudo do problema dos Lugares de Memória no pós-abolição.
\end{abstract}

PALAVRAS-CHAVE: Salvador; Manuel Querino; Lugares de Memória; Pós-Abolição.

\section{Memories of a delusion: Manuel Querino and Salvador's urban reforms (1912-1916)}

ABSTRACT: This article presents a historiographical analysis oriented by the idea of Places of Memory, in the sense proposed by Pierre Nora, in the context of post-abolition in Salvador, Bahia. For this purpose, it is approximated the urban reforms carried out in the city between 1912 and 1916 and its descriptions presented in the memorialistic book Bahia de Outrora, published in 1916 by the black intellectual Manuel Querino. In this analysis, it is used the notion of Cultural Arena, proposed by Richard Morse in the context of urban history, which approaches the implantation of modern projects by their culture products. This notion is re-elaborated from the idea of subalternity present in Spivak, faced by the differences of race and class presented in the analysis. Finally, it is observed how Querino's literature, based on these categories, may contribute to the study of the Places of Memory in the context of the post-abolition.

KEYWORDS: Salvador; Manuel Querino; Places of Memory; Post-Abolition.

\section{Memorias de una desilusión: Manuel Querino y las reformas urbanas de Salvador (1912-1916)}

RESUMEN: Este articulo presenta un análisis historiográfico de los Lugares de Memoria, en el sentido propuesto por Pierre Nora, asociado al contexto de la post-abolición en Salvador, Bahia. Para este propósito, las reformas urbanas llevadas a cabo en la ciudad entre 1912 y 1916 son aproximadas a las descripciones presentes en el libro Bahia de Outrora, publicado por el intelectual negro Manuel Querino en 1916. En este análisis, se utiliza la noción de Arena Cultural, propuesta por Richard Morse en el contexto de la historia urbana, en la cual se propone analizar la implantación de proyectos modernos por sus productos culturales. Frente a las diferencias de raza y clase presentes en el análisis, esta noción fue reelaborada a partir de la idea de subalternidad de Spivak. Finalmente, se observa como la literatura de Querino puede contribuir a los estudios de los Lugares de Memoria en el contexto de la post-abolición. Palabras-clave: Salvador; Manuel Querino; Lugares de Memoria; PostAbolícion.

PALABRAS CLAVE: Salvador; Manuel Querino; Lugares de memoria; Después de la abolición.

\footnotetext{
* Mestre em Estética e História da Arte pela Universidade de São Paulo. Atualmente, doutorando no Programa de Pós-Graduação em História do Instituto de Filosofia e Ciências Humanas da Unicamp. Contato: Universidade de São Paulo, Instituto de Filosofia e Ciências Humanas, Rua Cora Coralina 100, Cidade Universitária, CEP:13083-896 Campinas - SP, Brasil. brunopinheiro@usp.br
} 
Esse artigo parte de uma proposta realizada por Adrian Gorelik e Fernanda Âreas Peixoto a diversos intelectuais sul-americanos para a edição do livro Ciudades Sudamericanas como Arenas Culturales (2016): é possível pensar qualquer contexto urbano a partir da ideia de Arenas Culturais proposta por Richard Morse?

Essa noção, presente em As Cidades "Periféricas" como Arenas Culturais: Rússia, Austria, América Latina (1995), publicado originalmente em 1984 no Journal of Urban History, apresenta-se como proposta para entender a sociabilidade em torno da implantação de projetos de estado modernos. Ela diz respeito a uma atitude intelectual de buscar entender as cidades a partir dos vestígios produzidos por quem as experimenta, colocando os objetos de cultura produzidos nesses contextos em posição central nas análises que partem dessa perspectiva.

$\mathrm{Na}$ analise a ser realizada aqui, a cidade de Salvador será tomada como uma Arena Cultural "periférica", qual proposto por Morse, entendendo-a numa escala global, como uma das tantas cidades que passaram por processos de modernidade diversos àqueles dos centros da Europa rica e dos Estados Unidos. Contudo, será incorporada uma outra relação ao binômio Centro x Periferia numa escala local, buscando entender como se revela na cidade, enquanto Arena Cultural, experiências diversas de classe e raça, que por questões operacionais serão referenciadas por um segundo binômio, o da produção de Hegemonia e Subalternidade nas relações sociais. ${ }^{11}$ A partir dessa premissa, pretende-se avaliar como a proposição de Morse pode contribuir metodologicamente para se pensar os Lugares de Memória, na acepção de Pierre Nora, associados às populações negras periféricas. ${ }^{22}$

Essa proposição inicial surgiu a partir das observações realizadas pelo brasilianista Hendrik Kraay em "Frio como a pedra que há de se compor": caboclos e monumentos na comemoração da independência da Bahia (2013), em que avalia as diferentes mudanças nos festejos da Independência da Bahia durante as três últimas décadas do século XIX. Realizada para rememorar as lutas de independência do Brasil na Bahia de 1823, essa festa tinha um caráter eminentemente popular desde os seus primórdios. Kraay observa que em diferentes momentos, muitos deles marcados por redefinições da ordem social, como a abolição da escravidão e a proclamação da república, a ação do poder público sobre a festa se modificou. Esse foi o caso da reforma da Praça do Campo Grande, inaugurada no 2 de julho de 1895. A praça, que era o palco central do festejo até essa data, e que também assumia uma posição privilegiada entre as vizinhanças que as elites baianas passaram a ocupar no decorrer daquele século, passou a ter posicionada em seu centro uma imponente escultura realizada pelo 
escultor italiano Carlo Nicoli em que figurava o Caboclo, entidade que assumia a posição de herói popular mítico, que há décadas tinha sua versão em madeira passeando naquela data em um andor pelas rua da cidade e visitava diversos terreiros de Candomblé. Foi também a partir desse ano que o Campo Grande passou a ser utilizado nesse dia por festejos oficiais, organizados e policiados, enquanto que a festa popular passou a concentrar-se no Santo Antônio além do Carmo, bairro de edifícios coloniais, vistos como insalubres e de mal gosto, que, com a migração das elites para os bairros mais "modernos", passaram a ser ocupados pelas classes populares negras. A partir da análise realizada por Kraay, é possível inferir que os modos de territorialização negra na cidade pode ser entendidos enquanto negociada pelas classes populares negras junto aos grupos sociais hegemônicos, sem deixar de observar as assimetrias de poder envolvidas e seus potenciais conflitos. ${ }^{33}$

A partir desse arranjo de relações, será analisado aqui um caso posterior ao analisado por Kraay, mas que relaciona-se na história urbana da cidade como um desdobramento direto dele, enquanto parte da implantação de um projeto moderno na cidade, reformas urbanas realizadas em Salvador entre 1912 e 1916 pelo governador José Joaquim Seabra. Inspiradas nas intervenções urbanísticas de "bota abaixo" realizadas pelo barão Haussmann em Paris e popularizadas no Brasil por Pereira Passos no Rio de Janeiro, essas reformas foram centrais na definição de uma forma de cidade e modos de ocupação que tem ecos até o tempo presente no que se entende hoje como a região central de Salvador. Do modo proposto por Morse, essas reformas serão analisadas a partir da produção do intelectual negro Manuel Querino contemporânea a elas. Pintor-decorador desde a década de 1870, Querino foi professor de desenho geométrico por cerca de quarenta anos, e funcionário na Secretária de Agricultura, Viação, Indústria e Obras Públicas entre 1893 e 1916, além de ter atuado como militante negro e operário entre 1870 e 1900. Dado sua trajetória, sua produção bibliográfica será entendida aqui como um espaço privilegiado para entender uma parcela da vida cultural das classes populares negras de Salvador frente a essas reformas. Desse modo, dados relacionados à vida urbana na Bahia do período serão aproximados nesse artigo às descrições presentes no livro Bahia de Outrora, publicado por Querino em 1916, ano em que a reforma de Seabra foi finalizada. A partir dessa análise, pretende-se concluir com uma avaliação de como a experiência de Querino nessa publicação pode contribuir ao debate sobre Lugares de Memória associados ao recorte racial e de classe que ele pertencia. 


\section{As reformas urbanas de Salvador como marco temporal}

Ao tratar do projeto da Praça do Campo Grande, Kraay revela alguns debates públicos acerca de sua definição. A decisão pela escultura do Caboclo como figura central teria sido fruto de uma acirrada disputa entre aqueles que acreditavam ser incabível um personagem não-branco protagonizar os sentimentos cívicos de um projeto republicano que pretendia-se civilizado, e aqueles que, por estar intimamente ligado a valores há muito haviam se popularizado no interior das classes populares negras locais, acreditavam que ele era um marcador necessário para o projeto identitário local. Um outro debate sobre a definição do projeto apresentava-se quase que univocamente na defesa da ideia de tomar como positivo a implementação de soluções urbanas entendidas como modernizantes. A historiadora do urbanismo Eloísa Petti Pinheiro, que será tomada aqui como referência sobre o tema na Bahia, aponta essa ideia como guiada pelos valores de salubridade, fluidez e beleza. ${ }^{44}$ A partir deles, era defendida a destruição de imoveis de qualquer uso para a implantação de redes de esgoto, o alargamento de vias, ou a mera implementação de códigos visuais da arquitetura e do urbanismo que se popularizavam internacionalmente. ${ }^{55}$ Essa forma urbana, associada a projetos republicanos, por seu parentesco com a Republique Française, ganhou contornos em diversas cidades no país, como Salvador, de um padrão estético estabelecido em recusa aos valores coloniais e escravocratas. A partir desses fundamentos, foram demolidos edifícios públicos, comerciais e residenciais. Dos últimos, é significativo que foram atingidos, majoritariamente, moradias de vizinhanças de ocupação popular e negra, que viviam encortiçados nos casarões que no período colonial eram ocupados pelas elites da cidade.

Em Salvador, esses debates orientaram uma série de reformas pontuais que ganharam força após a proclamação da república, como parte da ideia de sua construção, aumentando em escala entre 1912 e 1916. Nesse período, a forma de seu tecido urbano e seus usos foram profundamente redefinidos, num processo que teve como principal articulador José Joaquim Seabra, governador eleito na Bahia em 1912. Seabra foi ministro da Justiça e Negócios do governo Rodrigues Alves, entre 1902 e 1906, acompanhando de perto as reformas de Pereira Passos, e Ministro dos Transportes de Hermes da Fonseca entre 1910 e 1912. Sua passagem por altos cargos do governo federal é um indício do grande capital político que disponibilizava para viabilizar a articulação das três esferas do poder, empresários enriquecidos pela economia do cacau no sul do estado, e o capital internacional.

Houveram dois grandes focos de intervenções urbanas nesses quatro anos. Por um lado, ela incidiu na reorganização da região do Porto. Localizada na Cidade Baixa, essa região 
teve diversos edifícios destruídos, majoritariamente armazéns comerciais, para estabelecer uma planta em quadricula, com o fim de ampliar e otimizar os espaços úteis para a finalidade portuária. Por outro lado, houve a abertura da Avenida Sete de Setembro. Essa, tinha como fim produzir um eixo que cortasse longitudinalmente as regiões comerciais e residenciais da Cidade Alta. Sua construção foi resultado da retificação e alargamento de diversas vias preexistentes, de modo que não houveram quarteirões inteiros sendo demolidos, mas um grande número de edifícios pontuais. Ela tinha como fim articular o fluxo do transporte entre os diferentes bairros, de modo que a elite local que ao longo de quase todo o século XIX passou a morar em bairros mais distantes do comércio e da região administrativa da cidade pudesse transitar com facilidade entre essas diferentes zonas.

No caso da Avenida Sete, as escolhas em relação à sua forma incidiram diretamente na territorialização da riqueza e da pobreza, produzindo processos de segregação de classe e raça. Esse processo afetou as classes subalternas não apenas no modo como se relacionam materialmente com a cidade, mas também nos seus usos. Desse modo, é possível evidenciar nessas reformas um sentido disciplinador, alinhando-se com o que Pinheiro evidencia que, no período, entendia-se como uma sociedade ordenada. Essa ideia de ordem teve um caráter altamente racializado no pós-abolição baiano. Nesse sentido, é significativo que, a partir da década de 1890, os campos do sanitarismo e medicina legal, que foram centrais para o debate urbano acerca dessa ideia, foram profundamente influenciados pelos estudos das raças humanas de matriz evolucionista. Nina Rodrigues, que foi professor dessas duas cadeiras em momentos diferentes na Faculdade de Medicina da Bahia, foi central na popularização no país dos autores da Escola Italiana de Criminalística, que tomavam como possibilidade, a definição de caracteres físicos próprios à propensão para a delinquencia (Schwarcz, 1997). Esse sistema de crenças possibilitou o surgimento de uma percepção que associava a própria presença de negros na vida social brasileira ao passado colonial escravocrata, contrário à modernização. Desse modo, produziu-se uma série de ações institucionais que buscavam, em diversas escalas, redefinir os espaços públicos a serem ocupados pelas populações negras, impelindo-as a renegociar sua ocupação na cidade a partir de novos códigos de conduta, que incidiam sobre práticas sociais cotidianas ou razonais como as festas populares, o batuque e a capoeira. ${ }^{66}$ 


\section{Manuel Querino, do projeto de uma República Negra e Popular, à sua desilusão}

Com o fim de embelezar a cidade, o Intendente Municipal, Júlio Viveiros Brandão decidiu pela contratação, em 1912, de arquitetos, escultores e pintores-decoradores que atuavam em São Paulo, alinhados com os códigos arquitetônicos difundidos nos grandes centros, grupo composto majoritariamente por imigrantes italianos. Esse dado foi observado na fortuna crítica sobre a história do urbanismo na Bahia tanto por Pinheiro, quanto por Maria das Graças Leal em sua pesquisa biográfica sobre o pintor-decorador Manuel Raymundo Querino, homem negro que trabalhou entre 1893 e 1916 na secretária de Agricultura, Viação, Indústria e Obras Públicas. ${ }^{77}$

Durante o período das reformas de Seabra, Querino ocupava a posição de um funcionário público afastado de seu campo de trabalho, vivendo um relativo ostracismo político após mais de duas décadas de militância das causas negra e operária iniciada em 1876. Em 1900, a atividade política deu lugar à produção intelectual que, como observou Leal, apesar de diversa, tem como um dos temas recorrentes a desilusão frente ao modo como foi implementado o projeto republicano, que ele entedia como desvinculado aos interesses das classes trabalhadoras negras de Salvador.

Numa análise breve da trajetória intelectual de Querino, é significativo que esse sentido de desilusão pode ser entendido a partir de seu compromisso íntimo com as ideias republicanas e a posterior precarização material de sua vida e de pessoas conhecidas com experiências sociais próximas às dele. Querino nasceu em 1951, de uma mulher negra solteira de Santo Amaro da Purificação, tornando-se orfão nos seus primeiros anos de vida. Foi encaminhado ao juiz de órfãos que o encaminhou para o professor Manoel Correa Garcia, que se tornou seu tutor até os 16 ou 17 anos de idade. Garcia estudou educação na Escola Normal de Paris e doutorou-se em filosofia na Universidade de Tubingue, tendo atuado na Bahia em diversos órgãos públicos de educação. Foi nesse período que Querino teve contato com os debates sobre o lugar das instituições de ensino no projeto republicano, além de ter recebido treinamento como pintor-decorador. Ao deixar a casa de Garcia, Querino realizou uma viagem pelos estados do nordeste brasileiro, quando foi alistado pelo exército brasileiro no sertão do Piaui para servir na Guerra do Paraguai, cujo recrutamento mirava em homens jovens negros. Por ser letrado, foi alocado no Paraguai como escriturário do batalhão, servindo por pouco mais de um ano, voltando para Salvador em setembro de 1870.

De volta à Bahia, Querino passou a trabalhar como pintor-decorador durante o dia, e estudar à noite. Em 1872, Ingressou nos estudos preparatórios do recém-criado Liceu de Artes 
e Ofícios, instituição voltada à formação profissional e humanística das classes populares. Em 1977, participou da reforma do solar Jonathas Abbot, onde iria ser instalada a Acadêmia de Bellas Artes. Ele se matriculou na instituição, formando-se em desenho em 1882, além de ter cursado arquitetura, que não concluiu por falta de professores para ministrar disciplinas técnicas obrigatórias. Após terminar o curso de desenho, Querino passou a lecionar essa disciplina no Liceu, onde atuou até 1900, e no Colégio Casa Pia dos Órfãos de São Joaquim, voltada para crianças e jovens orfãos, permanecendo nele por toda a vida. Seu engajamento nos processos de educação formal estava diretamente relacionado à sua militância política, de modo que ele entendia o acesso ao ensino como uma ferramenta de possível emancipação dos trabalhadores negros, seja em sua vertente profissionalizante, que promoveria autonomia material, seja em sua vertente humanística, que permitiria o acesso à retórica republicana.

Querino foi membro atuante da Liga Operária Bahiana desde sua fundação, em 1876, tornando-se uma das principais lideranças na transformação da agremiação em junho de 1890 no Partido Operário. Filiado ao partido, ele ocupou o Conselho Municipal entre 1891 e 1893, como indicado, e 1897 e 1899, mediante eleições. Após 1900, Querino afastou-se completamente da vida política, passando a dividir suas atividades de funcionário público e professor com a de escritor e pesquisador.

Seu primeiro livro foi Desenho Linear das Classes Elementares (1903), um manual de ensino de desenho técnico, gênero de publicação que foi retomado por ele em Elementos do Desenho Geométrico (1911). Publicou também dois livros de história da arte na Bahia, As Artes na Bahia (1909) e Artistas Baianos - indicações biográficas (1909), que, por revelar uma preocupação com as condições materiais do trabalho de artista e suas relações, são descritos por Leal como uma produção que pode ser aproximada da história social da arte e da história do trabalho. Em 1916, ele publicou o livro Bahia de Outrora - Fatos e Vultos Populares, composto de descrições de costumes observados em diferentes grupos sociais da população baiana, e A Raça Africana e seus costumes na Bahia (1916). Em seguida, publicou seu último livro, O Colono Preto como fator de Civilização Brasileira (1918). Nesses dois últimos, ele assume uma atitude antagônica em relação àquela alinhada ao pensamento racial hegemônico, popularizado por Nina Rodrigues, que entendia a população negra do Brasil como um obstáculo para sua modernização. Querino foi também colaborador da revista do Instituto Histórico e Geográfico da Bahia, cujo texto de maior circulação posterior foi $O$ Homem de Cor Preta na História (1923), além de ter escrito um livro publicado cinco anos após o seu falecimento, A Arte Culinária (1928), referenciado nos estudos de história da 
alimentação como o primeiro livro de receitas que apresentava os pratos afro-religiosos que posteriormente foram incorporados ao projeto identitário baiano.

Leal observa, no conjunto da obra de Querino, diferentes facetas do projeto republicano que ele se alinhava, interessado pela possibilidade de crescimento da participação política, social e cultural do trabalhador negro. Em sua leitura, a autora aponta que é possível inferir que a dissonância entre a percepção de Querino do que deveria ser o projeto republicano e o modo como ele foi aplicado é definidora de um sentimento de desilusão que se reflete de modos distintos em cada um de seus livros. Esse sentimento revela-se algumas vezes de modo bastante enérgico em Bahia de Outrora, como quando fala em "despotismo republicano" ao comentar os rumos das comemorações do 2 de Julho, que perdeu espaço a partir de 1900 em detrimento do do processo de centralização dos sentimentos cívicos relacionados à Independência no 7 de Setembro, sendo retomada apenas em 1943, como comenta em nota o editor da terceira edição do livro.

\section{A Bahia de Outrora: Querino frente à construção da República}

O primeiro indício de que a publicação de Bahia de Outrora e a reforma urbana realizada em Salvador poderiam fazer parte de um mesmo problema, ligado à redefinição dos usos da cidade e, consequentemente, das Arenas Culturais que se delineiam em seu interior, é sua coincidência no tempo. Em seguida, é significativo as relações profissionais diretas de seu autor com a arquitetura e o urbanismo. Por fim, chama a atenção o desalinho entre posições assumidas pelo autor e pela retórica que definia o que significava ter uma cidade ordenada. Desse modo, será realizada a seguir uma aproximação entre as descrições que Querino publicou e aquelas presentes na historiografia urbana associada a Salvador.

A primeira impressão, ao ler o livro frente ao contexto da reforma de Seabra, é que ele não faz nenhuma menção ao desenho novo da cidade. O livro é composto de um conjunto de textos, parte deles publicados anteriormente, parte inéditos, que tratam de uma variedade de temas associados à sociabilidade e a memória dos diferentes grupos sociais da capital baiana. Essas descrições apresentam uma temporalidade difusa, que atravessa grande parte do século XIX. Essa amplitude temporal e temática resulta em uma diversidade de assuntos como a implantação das primeiras oficinas litográficas na Bahia, os rituais religiosos públicos, a memória dos veteranos da Guerra do Paraguai e as trajetórias de intelectuais oriundos das classes populares negras. Em quase nenhuma dessas descrições, o plano da cidade se define 
como um problema, ainda que os usos do espaço público sejam constantemente colocados em questão.

Nessa diversidade de textos, o padrão temática mais visível é o de que, das 59 descrições, 25 referem-se a práticas festivas, sejam elas realizadas em ambiente público (a maioria delas) ou privado. Dessas, onze tratam de festividades abertamente religiosas (das quais apenas uma dela identificava-se abertamente como afro-religiosa), e treze leigas, sendo que esse caráter diz respeito à uma predominância de um desses dois polos em sua retórica, visto que quase todas elas tinham em sua forma elementos de ambos os léxicos.

No conjunto completo dos textos, ele utiliza poucos marcadores de diferença. Marcadores étnico-raciais são raros, sendo que o mais significante deles está presente no texto A Moda Carijó. Nele, Querino descreve três anedotas sobre trabalhadores, que visa advogar em defesa do trabalhador africano que seria subvalorizado, apesar de suas habilidades, em detrimento de um trabalhador imigrante francês, supervalorizado, apesar de sua ineficiência. Marcadores de gênero tornam-se mais vezes como definidores de problemas. Eles são utilizados em três momentos para evidenciar aspectos da implantação de um projeto de modernidade local. Em todos os casos, ela descreve uma antiga ordem, em que competia às mulheres a vida privada, e ao homem, a vida pública, de modo que a ocupação de determinados espaços tradicionalmente masculinos, como a rua, era tomado como principal marcador dessa mudança. Nessas descrições, Querino alterna posições de euforia e desacordo em relação a esses processos.

As mudanças entre o passado e o presente se revelam em textos de diversos outros temas, configurando-se como uma das questões que nesse livro ele constrói as argumentações mais elaboradas. Em relação a ela, Querino assume posições diversas, a depender de que aspecto desse processo que ele trata. No texto em que descreve a trajetória do político liberal Cipriano Barata, ele aproxima os processos de representação política da seguinte maneira:

\footnotetext{
Nos tempos ingratos do obscurantismo, muito antes de surgir o raio de luz dessa civilização elétrica que deslumbra, mas não edifica; que proporciona a decadência do caráter, que transforma os bons costumes em baixo interesse, elevando-o à altura de um princípio, o povo possuía seus eleitos, seus patriarcas, aos quais ouvia com respeito, acatava suas decisões, agindo com desvanecimento e acertando, porque o povo nunca se engana. Diz-se que o povo não sabe escolher bem, é puro engano; erra quem decide em nome dele sem consultá-lo. (Querino, 1946: 158)
}

No texto, ele expressa um fatalismo em relação à ideia difundida, seja "nos tempos ingratos do obscurantismo", seja na "civilização elétrica", de que a representatividade política 
das classes populares poderia ser de alguma maneira danosa ao estado, de modo que sua prática política deveria ser limitada. Essa percepção de Querino sobre as ideias difundidas em seu tempo, que não mudaram junto com a mudança do sistema político, define sua atitude raivosa, presente também em A Cumbuca Eleitoral, em que ele descreve de modo jocoso o processo eleitoral no período anterior à instituição da Lei Saraiva, de 1881, em que ele era definido em grandes festas públicas financiadas pelos candidatos.

Em outros textos, Querino assume posições mais conciliatórias, como na introdução do texto Cantor de Modinhas.

\begin{abstract}
Como tudo mudou, já não se encontram mais os palanques, as cadeiras de arruar, as liteiras, as andorinhas, as gôndolas e a machambomba.

Os meios de transporte são outros, mais compatíveis com o evoluir do século: o automóvel e a motocicleta. Dois dias idos e ninguém andará mais de cab; os passeios serão feitos em aeroplanos, indo-se, às tardes frescas por sobre as vilas e povoados, com a segurança de quem palmilha por estrada macadamizada.

E tudo isto é obra do Progresso. Quando ele aparece numa cidade tudo se transforma, os usos e os costumes dos velhos somem-se, para as novidades imperar.

(...)

Tudo isto é bom. Mas eu, que fui criado vendo o andador das almas pedindo - uma esmola para as almas santas e benditas do purgatório, nas segundas-feiras, metido em sua capa verde e com a bolsa com a estampa de prata para a gente beijar, tenho saudade desses dias que passaram na voragem do tempo. (Querino, 1946: 260-261)
\end{abstract}

Nele, Querino elabora um jogo que dura três páginas, em que salienta diferenças entre práticas sociais diversas do passado e do presente, que vão de hábitos alimentares aos meios de transporte. Nesse excerto, seu fatalismo se expressa ao localizar-se como um sujeito fora do tempo, que é acentuado em introduzir nele uma breve visão de futuro, ainda mais irreconhecível à sua noção de realidade, que se revela como envolta num excesso de passado, que é constante no livro.

Esse fatalismo, que pode ser visto como uma face de sua desilusão com o projeto republicano, pode ser entendido a partir da centralidade que as festas populares assumem no livro. Para pensar essa questão, me interessa num primeiro momento lembrar que no período das reformas de Seabra, foram demolidas diversas igrejas do período colonial, especialmente nas obras da construção da Avenida Sete de Setembro. Juntamente à destruição desses objetos que atuavam como importantes marcos visuais da paisagem urbana da cidade, foram redefinidas as práticas festivas que os utilizavam como eixo. Esse processo ocorreu não apenas por conta da reorganização física desses espaços, mas também de uma redefinição do calendário festivo da cidade, estabelecido a partir de negociações entre diversas instâncias do poder público e eclesiástico e diferentes setores da sociedade civil. Desse modo, não somente 
o 2 de Julho perdeu espaço para o 7 de Setembro, mas diversas atividades festivas descritas por Querino, sejam religiosas ou civis, associadas aos períodos colonial e imperial, deixaram de existir. Querino associa uma perda de sentido de comunidade ao fim ou redefinição dessas práticas que tinham como palco a cidade, produzindo novas relações urbanas. Essas tomam forma em seu texto nas novas relações de anonimato decorrentes da falta de referencial simbólico, que ele trata em alguns dos seus textos como experiência social centralizadora do fatalismo presente no livro.

Essa relação entre a dimensão física da cidade e seus possíveis usos podem ser entendidas a partir de seu caráter disciplinador, que agiu sobre diversas práticas culturais, cotidianas ou sazonais das populações negras locais, com a justificativa de que esse processo faria parte do caminho em direção à civilidade. Esse processo produzia descontinuidades em determinados usos do espaço urbano mediado pela memória, como os das diversas descrições de Querino de festas populares e ritos religiosos que hoje são desconhecidos. De modo significativo, houve uma redefinição do calendário das festas populares em Salvador a partir de 1946, descrito pelo brasilianista norte-americano Scott Ickes, African-Brazilian Culture and regional identity in Bahia (2013). Assim como no artigo de Kraay, sua leitura dessas manifestações incidem sobre seus usos políticos, sendo entendidas como palco da expressão de uma agenda política popular e negra, onde esses setores da sociedade negociavam com as classes hegemônicas seus sentidos e espaços.

\section{Considerações Finais}

Na aproximação com o livro Bahia de Outrora, o silêncio do autor acerca dos processos de redefinição física da cidade é surpreendente. Esse silêncio pode ser entendido de diversas maneiras. Partindo da hipótese da desilusão, intuído pelo prefaciador da terceira edição do livro, que diz ser a escrita "um refúgio de sua desilusão política", ela pode ser entendida como resultante de sua vontade não realizada em tomar parte de um projeto republicano que fizesse uso das tecnologias urbanas que permitiam melhor salubridade, fluidez e beleza, como observou Leal em suas outras publicações, com o fim de promover a emancipação material e política das classes populares negras de Salvador. Num caminho diverso, esse mesmo silêncio pode ser tomado como de sentido indeterminado, por conta das limitações da seleção desse produto editorial como único documento de análise. Desse modo, podemos apontar problemas acerca do desconhecimento de dados acerca do contexto de 
produção, circulação e consumo de livros no período, que definia, a partir de interesses que vão de alinhamentos políticos das empresas ao perfil dos consumidores de livros, o que seria ou não passível de ser publicado.

Tomando a primeira hipótese como verdade, é possível entender esse silêncio de Querino como uma saída de cena, ou perda de espaço das classes populares negras na cidade, ainda que essa leitura metonímica do conteúdo de seu livro não leve em conta, como apontado acima, as relações produtivas no campo editorial. De qualquer modo, é significativo que esse silêncio ocorre concomitante a diversos processos de silenciamento, seja de manifestações das culturas populares negras que ocorriam na cidade, seja do próprio Querino enquanto intelectual, que por sua experiência social não possibilitar a ele alinhar-se com parte das posições hegemônicas no período, passou por um processo de esquecimento, que foi revisitado poucas vezes, sendo que uma das mais significativas teve a forma ficcional, no romance Tenda dos Milagres (1964), de Jorge Amado, em que o autor descreve as dinâmicas de subalternização de um intelectual negro na Bahia, frente a um pensamento hegemônico racista e classista.

Retomando o problema proposto no início do artigo, é possível concluir que, enquanto chave para analisar um contexto de implantação de um projeto de modernidade, a proposição de Morse se revela como bastante útil para pensar em como as mudanças no tecido urbano impôs, a partir das dinâmicas de subalternidade, novas formas de territorialização das populações negras no contexto do pós-abolição, redefinindo suas relações simbólicas e seu costumes e, consequentemente, reelaborando seus Lugares de Memória. Nesse sentido, a análise de Bahia de Outrora realizada aqui revela indícios ainda pontuais nesse sentido, sendo que uma aproximação mais pormenorizada de sua produção bibliográfica permitiria realizar uma leitura mais bem delineada dos espaços assumidos por essas populações na Salvador republicana. A aproximação com a produção de Querino pode trazer grandes ganhos numa analise historiográfica dos Lugares de Memória das populações negras do pós-abolição à maneira feita por Matos, Abreu e Guran no que se refere àqueles associados aos africanos escravizados. ${ }^{88}$ Desse modo, sua literatura, que, como evidenciou Leal, ao longo do século XX foi tratada como memorialística, sendo descartada de debates acadêmicos por carecer do rigor formal próprio do campo universitário, assume um lugar privilegiado frente à escassez de documentação que deem conta da vida cultural das classes populares negras a partir de sua própria perspectiva, problema oriundo do fato de que as escolhas do que é passível de 
preservação nas instituições de memória privilegiaram históricamente documentos associados às elites nacionais.

\section{Notas}

\footnotetext{
${ }^{1}$ Entende-se aqui essa operação, de origem Gramsciana, à maneira organizada pela filósofa indiana Gayatri Spivak em Pode o Subalterno Falar? (1977; 2010), que a utiliza para posicionar o discurso das mulheres hindus em relação aos homens brancos e aos homens hindus, que devido às hierarquias estabelecidas por suas experiências ligadas às diferenças de gênero, raça, classe e nacionalidade, vivem em constante negociação acerca dos seus espaços e sentidos.

${ }^{2}$ NORA, Pierre. Entre Memória e História: a problemática dos Lugares. Projeto História PUC-SP, São Paulo, V.10, 1993.

${ }^{3}$ A expressão Territorialidade Negra foi utilizado por Wilson Roberto de Mattos em Negros contra a ordem: Astúcias, Resistências e Liberdades possíveis (Salvador, 1850-1888) (2008) para tratar dos modos de ocupação da cidade específicos das populações negras de Salvador, que prevê a negociação de seus espaços pelos grupos politicamente hegemônicos, brancos, da cidade.

${ }^{4}$ Pinheiro, Eloísa Petti, Europa, França e Bahia - Difusão e adaptação de modelos urbanos (Paris, Rio e Salvador). Salvador, Edufba, 2002.

${ }^{5}$ Nesse sentido, é significativo em relação ao nível de difusão dessa ideia de cidade que, em 1933 a Antiga Sé de Salvador, um edifício barroco do século XVII, foi demolida para a implantação de trilhos de bondes. Esse dado revela também o estado prematuro em que os debates sobre patrimônio construído estava na região.

${ }^{6}$ A perseguição à capoeira e aos terreiros de Candomblé pelo poder público começaram imediatamente após à abolição com a justificativa de manter a ordem pública. A sua presença na cidade só voltou a ser renegociada a partir de meados da década de 1930, sendo que essas práticas culturais só se sedimentaram no projeto identitário de baianidade a partir de 1946, como observa Ickes em Afro-Brazilian Culture and Regional Identity in Bahia (2013).

${ }^{7}$ Leal, Maria das Graças. Manuel Querino, entre letras e lutas - Bahia, 1851-1923. São Paulo: Annablume, 2009.

${ }^{8}$ MATTOS, Hebe; ABREU, Martha; GURAN, Milton. Por uma história pública dos africanos escravizados. Estudos Históricos. 2014, v. 27, n. 14.
}

\section{Referências Bibliográficas}

GORELIK, Adrián; PEIXOTO, Fernanda Arêas. Ciudades Sudamericanas como Arenas Culturales. Buenos Aires: Siglo Veinteuno Editores, 2016.

GUIMARÃES, Antonio Sérgio Alfredo. Manuel Querino e a formação do "Pensamento Negro” no Brasil, 1890-1920. 28 Encontro Nacional da ANPOCS, Caxambu, 2004.

ICKES, Scott. African-Brazilian Culture and regional identity in Bahia, Brazil. Gainesville: University of Florida Press, 2013.

KRAAY, Hendrik. "Frio como a pedra que se há de compor": caboclos e monumentos na comemoração da Independência da Bahia, 1870-1900. Tempo - Revista do Departamento de História da UFF, Niterói, V.14, pp.51-81, 2013.

LEAL, Maria das Graças. Manuel Querino, entre letras e lutas - Bahia, 1851-1923. São Paulo: Annablume, 2009.

MATTOS, Hebe; ABREU, Martha; GURAN, Milton. Por uma história pública dos africanos escravizados. Estudos Históricos, Rio de Janeiro, v. 27, n. 14, 2014.

MATTOS, Wilson Roberto de. Negros contra a ordem: Astúcias, Resistências e Liberdades possíveis (Salvador, 1850-1888). Salvador: Edufba, 2008. 
MORSE, Richard. As Cidades "Periféricas"como Arenas Culturais: Rússia, Áustria, América Latina. Estudos Históricos, São Paulo, V.8, no.16, pp.205-225, 1995.

NORA, Pierre. Entre Memória e História: a problemática dos Lugares. Projeto História PUC-SP, São Paulo, V.10, 1993.

PINHEIRO, Bruno. Uma Bahia em Construção: Odorico Tavares e Pierre Verger na revista O Cruzeiro (1946-1951). Dissertação (Mestrado em Estética e História da Arte) - MAC-USP, São Paulo. 2017.

PINHEIRO, Eloísa Petti. Europa, França e Bahia - Difusão e adaptação de modelos urbanos (Paris, Rio e Salvador). Salvador: Edufba, 2002.

SPIVAK, Gayatri Chakravorty. Pode o Subalterno falar? Belo Horizonte: Editora UFMG, 2010.

SCHWARCZ, Lilia K. M. O Espetáculo das Raças. Cientistas, Instituições e Pensamento Racial No Brasil: 1870-1930. São Paulo: Companhia das Letras, 1993.

\section{Fontes Documentais:}

AMADO, Jorge. Tenda dos Milagres. 37. ed. Rio de Janeiro: Record, 1983.

QUERINO, Manuel. Bahia de Outrora: vultos e fatos populares. 3. ed. Salvador: Livraria Progesso, 1946. 